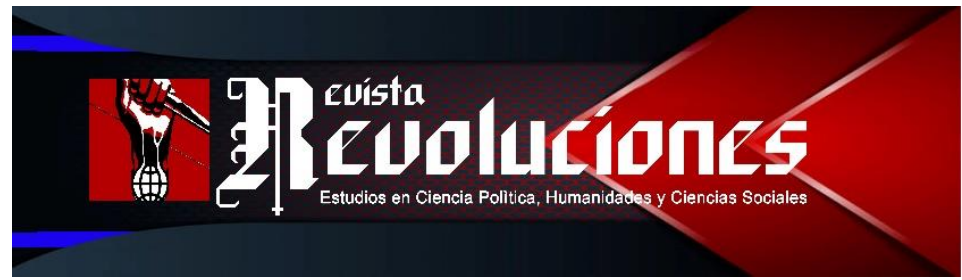

\title{
EDITORIAL
}

\section{Y EL PERRO SE LEVANTÓ DESPUÉS DE LA MUERTE: APUNTES EN DEFENSA DE LA OTRA ESPECIE}

\section{And the dog rose after death: notes in defense of the other species}

\author{
Jesús Wiliam Huanca-Arohuanca1 \\ UNIVERSIDAD NACIONAL DE SAN AGUSTÍN DE AREQUIPA \\ PERÚ \\ jhuancaar@unsa.edu.pe \\ https://orcid.org/oooo-0002-7353-1166
}

DOI: https://doi.org/10.35622/j.rr.2021.06.001

Recibido: 01-VII-2021 / Aceptado: 16-X-2021 / Actualizado: 01-XI-2021

\section{Resumen}

Es trágico ver a la otra especie (animales) sucumbir ante el dolor de un accidente intencional provocado por los animales (humanos), sabiendo que la indiferencia de esta última variedad, no es más que puro rencor y egoísmo hacia sí mismo y hacia las otras especies. El propósito es reflexionar la inhumanidad que se presenta en los poseedores de la mayor racionalidad sin sentido y carente de hermandad hacia la especie que mejor sabe demostrar el amor y la fidelidad a pesar de no recibir lo mismo. Esa especie resguardó el planeta durante millones de años porque su corazón no contiene maldad, excepto de supervivencia. Sin embargo, llegó el hombre y lo cambió por otro lleno de oscuridad; hoy, si la otra especie muere, no importa, ya que, la prioridad es el legado infernal al que se denomina: humanos. De manera que, los

\footnotetext{
${ }^{1}$ Docente-Investigador del Consejo Nacional de Ciencia, Tecnología e Innovación y el Departamento de Filosofía con mención en Ética y Filosofía Política por la Universidad Nacional de San Agustín de Arequipa [UNSA]. Maestrante en la facultad de Ciencias Jurídicas en Derecho Procesal y Administración de Justicia por la Universidad Católica de Santa María [UCSM]. Docente de Ciencias Sociales, Sociólogo y maestrante en Investigación y Docencia Universitaria por la Universidad Nacional del Altiplano [UNA-P], Perú. En la actualidad dirige la Revista Revoluciones: Estudios en Ciencia Política, Humanidades y Sociales. Así mismo, es revisor de la Revista Educación y Sociedad de la Universidad Ciego de Ávila Máximo Gómez Báez, Cuba. Sus principales líneas de investigación se desprenden en el marco de la teoría del poder, la epistemología, la filosofía decolonial, las políticas neoliberales, dinámicas educativas, las macroestructuras sociológicas y el planteamiento de un nuevo amuyawi para América Latina frente a los núcleos de poder colonial. Su impacto académico obedece a publicaciones de nivel internacional en las bases de datos Scopus, Web of Science y Scielo.
} 
ISSN: 2710-0499 ISSN-L: 2710-0480

pocos intentos de reformular el mundo, será un desafío para los pocos que mantienen su humanidad como principio de vida.

Palabras Clave: Animales, humanos, mundo, egoísmo, vida.

\begin{abstract}
It is tragic to see the other species (animals) succumb to the pain of an intentional accident caused by animals (humans), knowing that the indifference of this latter variety is nothing more than pure rencor and selfishness toward itself and the other species. The purpose is to reflect on the inhumanity that is presented in the holders of the greatest rationality without meaning and without brotherhood toward the species that best knows how to show love and fidelity despite not receiving the same thing. That species kept the planet for millions of years because its heart contains no evil, except survival. However, man arrived and changed him to another one full of darkness; today, if the other species dies, it does not matter, for the priority is the infernal legacy that is called: humans. So, the few attempts to reformulate the world will be a challenge for the few who maintain their humanity as the beginning of life.
\end{abstract}

Keyword: Animals, humans, world, selfishness, life.

\title{
DESARROLLO
}

Un respiro agónico y la mirada inocente con lágrimas que mojan el pavimento, dice; ayúdame por favor o mátame, ya no quiero sufrir más. Lo anterior corresponde a un trágico accidente que sufrió la especie que mejor ha demostrado el verdadero amor y fidelidad hacia una especie despreciable y egoísta que paga maltratándolo cada vez que lo ve. Él era en el pasado un lobo carroñero que se convirtió con las mentiras del hombre en un ser doméstico, pues dejó la furia para sentir el cariño del que le ofrecía un trozo de carne a cambio de muchas cosas. Por muchos siglos fueron guardianes, medios de transporte, gladiadores, mensajeros $\mathrm{y}$, sobre todo, compañeros de la especie indiferente e inhumano que en cada momento lo obliga a pelear su batalla a cambio de dinero. Nunca imaginaron que el hombre carente en su historia, les traccionaría de esa manera cobarde.

Ahora son conocidos simplemente como: "perros rabiosos". Hombres y mujeres lo desprecian y lo miran con todo su odio visceral: "fuera de aquí perro sarnoso" se escucha decir con frecuencia. Sin embargo, a pesar de recibir toda la maldad humana, siguen amando con más fuerza; en su mirada se puede encontrar la confianza y la tranquilidad. Ellos en el fondo pareciera que entienden lo que está sucediendo con la especie humana y por esa misma razón deciden mirarle de un lado a otro, para buscar una esperanza de humanidad. Pero tal parece que, solo buscan el cariño que le prometieron y, por otro lado, quizás de algún modo solo tienen hambre y por eso buscan alimentarse con las peores cosas sobrantes en los basurales y desechos, ya que, rota la promesa, solo queda subsistir sin molestar a los que siempre los hieren en donde están. De manera que, a pesar del desprecio de los hombres, seguirán siendo 
fieles y, su mirada inocente volverá una y otra vez como diciendo que la humanidad aún tiene esperanza de cambiar para bien.

Era una mañana trágica, donde su inocencia y alegría quiso ser plasmado a todos los hombres que viven amargados, pero para su mala suerte impactó con una máquina asesina conducido por un indiferente que ni se percató de lo que había hecho. Fue el momento más desconsolado para su especie, puesto que, intentaron ayudarlo con sus aullidos e intentaron rodear el pavimento oscuro e infernal, pero la condición no era favorable ni las máquinas respetaban el aullido tétrico de los antiguos lobos. Mientras seguía abandonado en medio de la pista, con la fuerza de su alma y con la poca voluntad que le quedaba, intentaba ponerse de pie, solo que ese propósito nunca se daría porque el impacto del golpe había sido muy profundo y la muerte esperaba su compañía. Sus lágrimas salían y la sangre pintaba de color rojo el pavimento oscuro, y como es de suponer, la especie violenta sin humanidad, pasaba como si no sucediera nada, sólo sus hermanos de especie regresaban una y otra vez, como esperando que la recuperación sea rápida y seguir con la travesía.

Pasaron horas y la muerte aún no conseguía trascender al tierno ser. Quizás alguna humanidad se percató para darle alguna esperanza, lo sacó de la pista y al fin algunos con algo de humanidad vieron tal incidente, pero, como es habitual, solo miraron. Y de esa manera, la vida del que alguna vez fue un lobo ancestral con historia, hoy, estaba a punto de terminar como un simple perro doméstico, traicionado por la gente al cual le dio todo su amor. A continuación, véase la figura 1.

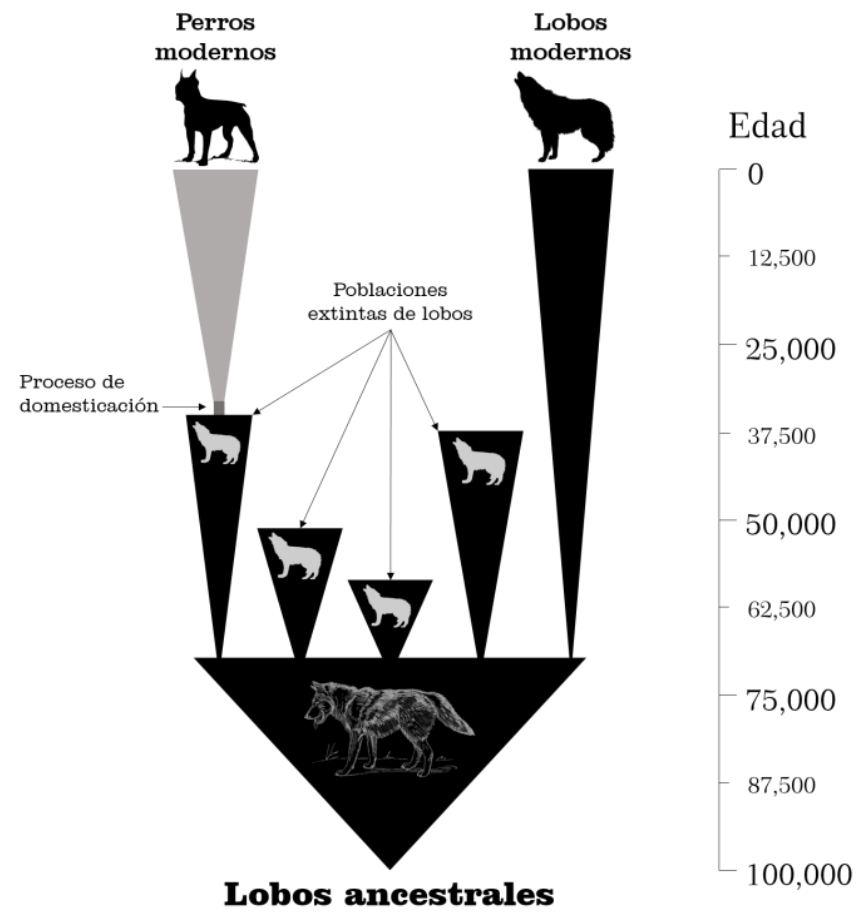

Figura 1. Historia de los lobos ancestrales

Fuente: https://www.sabermas.umich.mx/archivo/articulos/185-numero-2311/357-ide-donde-viene-tuperro-el-origen-de-los-perros-domesticos.html 
ISSN: 2710-0499 ISSN-L: 2710-0480

De lo precedente, se infiere que el origen evolutivo de los perros se remonta hacia aproximadamente 100.000 años atrás, desde su antecesor común con el lobo (Canis lupus) (Bentosela \& Mustaca, 2007) hasta el actual perro doméstico. Como se ve, los perros también manejan su propia historia diacrónica, hasta que hace más de 25.000 años se topó con el hombre que lleva el maligno dentro. Es de suponer, que el encuentro fue con engaños y de interés diferente, pues, bajo esa lógica, la especie de lobos no mintió y el hombre sí. Seguro es el peor engaño que una especie con intenciones negativas ha realizado a otro con finalidades completamente distintas. Porque los lobos terminaron dando todo a pesar de no recibir nada a cambio.

El hombre es malo desde el comienzo de su historia, es una especie que engaña, miente, odia, mata y saca ventaja en la mínima oportunidad que se le presenta. Casi todas las especies que lo acompañan han perecido como los perros domésticos y, otros que todavía no han entrado en contacto, todavía persisten, pero ya en la hegemonía de los que se creen los dueños del mundo. Concretamente, han fomentado guerras, saqueos, violaciones, combates y atentados hacia su propia especie y hacia los otros indefensos. No siendo suficiente todo lo anterior, para el 2020 han creado enfermedades y virus como el SAR-CoV-2 con fines claramente definidos para eliminar a los mismos y las otras que todavía persisten (Huanca-Arohuanca, 2020a; 2020b) 2021; 2022a; 2022b; Huanca-Arohuanca \& Núñez, 2020; Huanca-Arohuanca et al., 2020).

A medida que la civilización humana adopta la idea de ser dueño y amo del mundo, excluye a las otras especies o los somete a su dinámica egoísta. Lo que ocurrió con los lobos, es una clara explicación del cómo se comparta el hombre frente a la especie que obedece. Entonces, por todos los fenómenos de socialización y costumbre causi sacrílegos, hoy, se puede ver con normalidad la relación de amo y esclavo con cadenas (correa) paseando por las principales calles democráticas y promotores de la libertad. Por ende, surgen dos preguntas: ¿qué significa hoy llevar con correa a la especie que no va traicionar nunca al hombre? O ¿̇por qué la gente teme dar libertad a los perros domésticos?

La primera pregunta, lleva a la explicación del poder de unos sobre otros, es decir, llevar amarrado a una especie, representa dominio y como tal es la mejor forma de ejemplificar el temor hacia otros. Pareciera que es una amenaza a un supuesto enemigo, cuando dicen: mira cómo domino a este perro, igual pasaría contigo si cruzas mi línea. La segunda pregunta es crucial, porque los promotores de los principios máximos como; la libertad y democracia, en la realidad tácita temen que cualquier otra especie pueda derrocarles la hegemonía conseguida a través de mentiras, pero, más temen conocer la verdadera libertad y la otra forma de cómo se podría rearmar el planeta. Al respecto, Fleisner (2018) considera que las mascotas son satisfacciones irrestrictas de los humanos con egoísmo, pues han sido como pequeñas prostitutas $\mathrm{u}$ objetos de explotación psíquica y física del pensamiento antropocéntrico que busca hasta ahora justificar el lugar natural de los amos. 
Cuanto más se hace necesario los perros, ahora conocidos como mascotas, crece la cadena jerárquica de dominación. No existe consideración alguna a los lobos de la historia, a pesar de su influencia positiva en la salud y bienestar de los seres humanos (Gómez et al., 2007). Ellos seguirán expuesto a las órdenes de la inhumanidad y a los maltratos sin razón, porque la traición se paga con valentía; sin embargo, los hombres no están preparados para comprender eso.

Ahora conviene revisar algunas acciones y normativas diseñadas para romper la esclavitud animal. En Europa existe cierto abandono del concepto de cosa-animal, aunque sin dar una respuesta exacta sobre la naturaleza de los mismos. Para ello, puede servir los criterios usados en las legislaciones de Alemania, Austria, Checoslovaquia, Francia, Nueva Zelanda o Suiza, cuando la otra especie es catalogado como: seres sensibles. A pesar de no parecer un avance significativo, lo es, porque la lucha que se mantiene desde hace siglos está prosperando. Cabe mencionar que, desde hace doscientos años, las asociaciones animalistas con sostén jurídico se han multiplicado por todo el globo. Ejemplo de eso son The Vegetarian Society Portmouth, The Humanitarian League y Deutsche Verein für natürliche Lebensweisse (Santa, 2021).

Por su parte, en el caso peruano existe la Ley $\mathrm{N}^{0}$ 30407, donde en su artículo 3 denominado Ley de protección y bienestar animal, indica:

la presente ley tiene por objeto proteger la vida y la salud de los animales vertebrados, domésticos o silvestres mantenidos en cautiverio, impedir el maltrato, la crueldad, causados directa o indirectamente por el ser humano, que les ocasiona sufrimiento innecesario, lesión o muerte; así como fomentar el respeto a la vida y el bienestar de los animales a través de la educación. Además, de velar por su bienestar para prevenir accidentes a sus poblaciones y aquellas enfermedades transmisibles al ser humano (El Peruano, 2016, p. 1).

La normativa es irrestrictamente irrevocable y claro en cuanto se refiere a la relación de hombre/animal. Pues establece que los animales son seres sintientes no humanos con derecho a la vida y bienestar como necesidad de índole imperativa en el Perú (Vega \& Watanabe, 2016). Sin embargo, parece que la ley no es suficiente ni muy severo en sus sanciones, ya que es la única explicación del por qué aún existe tal grado de minimización y maltrato hacia las otras especies.

En cierta medida se ha visto la implantación de ciertos lineamientos como avance, pero no se ha visto una sanción de por medio a los infractores de dicha ley, ni se han presentados casos seguidos ante un tribunal para dar sentencia a esos individuos que siguen pensando que lo que se tiene en casa, es un objeto maleable y sin vida necesaria como para ser respetado. De manera que, lo que los lobos de la historia exigen al igual que muchas especies a la inhumanidad, solo puede tener un nombre y se llama: respeto.

\section{CONCLUSIÓN}


ISSN: 2710-0499 ISSN-L: 2710-0480

Desde cualquier ángulo de la acción humana frente a la otra especie, la indiferencia sigue más latente que nunca. No obstante, los pocos rastros de humanidad por aquellos pocos, puede hacer la diferencia, más todavía cuando existen indicios de indignación hacia el accionar incoherente y nefasto de algunos hombres en detrimento a la otra especie. Si se pretende instalar justicia y libertad en el mundo, la humanidad debe comenzar resolviendo los problemas domésticos, lo cual implica dar libertad al amigo fiel que espera el cuidado de los que se sienten sus dueños. Ellos solo quieren ser parte de la familia y están dispuestos a dar todo por ese hogar, tanto así que darían la vida por salvar al humano que alguna vez lo maltrató; porque ellos al final han dado lecciones de moralidad y hermandad a toda la civilización, pues su aporte es tan significativo que, la humanidad está en deuda con ellos.

\section{REFERENCIAS BIBLIOGRÁFICAS}

Bentosela, M., \& Mustaca, A. E. (2007). Comunicación entre perros y hombres. Revista $\begin{array}{llll}\text { Latinoamericana } \quad \text { Psicología, } & 39(2), & 375-387 .\end{array}$ https://www.redalyc.org/pdf/805/80539212.pdf

El Peruano. (2016). Ley de protección y bienestar animal. https://busquedas.elperuano.pe/normaslegales/ley-de-proteccion-y-bienestar-animal-ley-n30407-1331474-1/

Fleisner, P. (2018). Comunidades posthumanistas: dos ejemplos de vínculos no especistas entre canes $\mathrm{y}$ animales humanos en la literatura y en el cine latinoamericanos. $A L E A, 2 O(2), 36-52$. https://doi.org/10.1590/1517-106X/20182023652

Gómez, L., Atehortua, C., \& Orozco, S. (2007). La influencia de las mascotas en la vida humana. Revista Colombiana de Ciencias Pecuarias, 20(1), 377-386. http://www.scielo.org.co/pdf/rccp/v2on3/v2on3a16.pdf

Huanca-Arohuanca, J. W. (2020a). Caleidoscopio social al Covid-19: pánico y desesperación en tiempos de aislamiento. Revista Universidad y Sociedad, 12(6), 226-231. https://rus.ucf.edu.cu/index.php/rus/article/view/1836

Huanca-Arohuanca, J. W. (2020b). Cuando la muerte nos mira con deseo de llevarnos al tártaro. Revista Revoluciones, 2(2), 1-5. https://doi.org/10.35622/j.rr.2020.02.001

Huanca-Arohuanca, J. W. (2021). Un fantasma recorre el Perú del Bicentenario: lecciones y voluntad popular en las elecciones de 2021. Revista Revoluciones, 3(3), 1-4. https://doi.org/10.35622/j.rr.2021.03.001

Huanca-Arohuanca, J. W. (2022a). A 200 años de Independencia en el Perú y el papel de la historia contado desde la otredad. PURIQ, 4(1), 140-148. https://doi.org/10.37073/puriq.4.1.216

Huanca-Arohuanca, J. W. (2022b). El estado de la cuestión sobre la participación política en los jóvenes de la Nación Aymara - Perú. Un diálogo teórico desde sus actores. Apuntes Universitarios, 12(1).

Huanca-Arohuanca, J. W., \& Núñez, L. (2020). Estimaciones y contrastes de la pandemia en Perú y en el contexto mundial. Educare Et Comunicare. Revista Científica de La Facultad de Humanidades, 8(2), 10-20. https://doi.org/10.35383/educare.v8i2.440

Huanca-Arohuanca, J. W., Supo-Condori, F., Sucari, R., \& Supo, L. A. (2020). El problema social de la educación virtual universitaria en tiempos de pandemia, Perú. Revista Innovaciones Educativas, 22, 115-128. https://doi.org/10.22458/ie.v22iespecial.3218

Santa, L. (2021). ¿Qué es el derecho animal en el Perú? LPDERECHO.PE. https://lpderecho.pe/derecho-animal-peru/

Vega, S., \& Watanabe, R. (2016). Analysis of the Law 30407 «Law on Animal Protection and Welfare» in Peru. Revista de Investigaciones Veterinarias Del Perú, 27(2), 388-396. http://search.ebscohost.com/login.aspx?direct=true\&AuthType=cookie,ip,sso\&db=edssci\&AN =edssci.S1609.91172016000200023\&lang=es\&site=eds-live\&scope=site 